\title{
OS JOGOS E SUA CONTRIBUIÇÃO NA APRENDIZAGEM DA MATEMÁTICA
}

\section{ARTIGO ORIGINAL}

FARIAS, Mirian Zuqueto ${ }^{1}$

FARIAS, Mirian Zuqueto. Os jogos e sua contribuição na aprendizagem da matemática. Revista Científica Multidisciplinar Núcleo do Conhecimento. Ano 04, Ed. 06, Vol. 05, pp. 82-95. Junho de 2019. ISSN: 2448-0959

\section{RESUMO}

A disciplina de matemática é vista pelos alunos de forma temerosa,de difícil compreensão e que os conteúdos são complexos, contribuindo para as aulas se tornarem desinteressante. De acordo com esse contexto, fica difícil alcançar os objetivos tão almejados na sala de aula com os educandos, no processo ensino e aprendizagem. O presente trabalho, trata sobre as contribuições dos jogos matemáticos na aprendizagem dos educandos do $6^{\circ}$ ano do Fundamental II, numa perspectiva de contribuir no aperfeiçoamento das práticas pedagógicas nas aulas de matemática. Pois os jogos matemáticos é uma alternativa capaz de proporcionar aos educandos um ambiente mais favorável e prazeroso para aprender. A metodologia trata-se de uma revisão bibliográfica, na qual consistirá na coleta de referências de autores que fizeram suas pesquisas sobre o tema do trabalho citado acima, revistas, artigos científicos e outros materiais de características científicas. Esses dados são usados no estudo sob forma de citações, Esses dados são usados no estudo sob forma de citações, significando de embasamento para o desenvolvimento do assunto

${ }^{1}$ Licenciada em Matemática-UVA e Pedagogia-FAIARA, Pós-graduação em Gestão, Supervisão e Orientação Escolar-UNISONO, Especialista em Educação MatemáticaFAFAP, Educação Infantil e Alfabetização-FIB, Psicopedagogia Institucional-BARÃO DE MAUÁ-SP, Mestre em Ciências da Educação-USM e estudante de Doutorado em Ciências da Educação-UNR. 
pesquisado. Acredita-se que os Jogos são ferramentas cabíveis e palpáveis a Educação Matemática sendo de grande importância na aprendizagem da matemática.

Palavras-chave: jogos matemáticos, teorias da aprendizagem, práticas pedagógicas.

\section{INTRODUÇÃO}

Grande parte dos estudos e pesquisas realizada na área de Educação Matemática pressupõe que o uso dos jogos nos aulas de matemática, pressupõe uma mudança bastante apreciável no processo ensino e aprendizagem, que permite mudar o modelo de educação tradicional no ensino da matemática, o qual muitas das vezes, tem no livro didático os exercícios estandardizados, sendo o seu principal e único recurso pedagógico. Causando grande desinteresse por parte dos alunos em relação a disciplina. Sabe-se, que as práticas de ensino, são diferentes de escola para escola, mesmo quando se trata de disciplinas consideradas universais, como por exemplo, a matemática.

O objetivo desse trabalho, é que os jogos matemáticos venham contribuir com o aperfeiçoamento das práticas pedagógicas do professor. A metodologia utilizada nesse trabalho, trata-se de uma revisão bibliográfica, na qual consistirá na coleta de referências de autores que fizeram suas pesquisas sobre o tema do trabalho citado acima, revistas, artigos científicos e outros materiais de características científicas. Essas informações são usados na instrução sob forma de citações e também, significando de fundamento para o incremento do assunto pesquisado.

A importância de pesquisar essa temática justifica-se por se tratar de um tema interessante, principalmente na área da matemática. Pois os jogos tem uma relevância contribuição no avanço do processo ensino e aprendizagem no $6^{\circ}$ ano das séries finais do fundamental II, tornando-se relevante principalmente para futuros educadores da área.

Pois considera-se que os jogos estabelecem uma forma de aprendizagem significativa, constituindo uma maneira muito atrativa, envolvente e que proporciona 
também, benevolentes situações de aprendizagem instigando os educandos um modo diferente de aprender matemática favorecendo a criatividade, organizando métodos, resoluções de problemas e outros. E os erros deverão ser corrigidos de maneira natural durante o processo ou ação, sem deixar marcas. Lembrando ainda, que educação por meios de jogos tem se tornado, nas últimas décadas, uma alternativa metodológica bastante louvável e pode ser aplicada sob vários aspectos.

\section{FUNDAMENTAÇÃO TEÓRICA}

\subsection{APRENDIZAGEM MATEMÁTICA}

Segundo Lara (2003), a palavra matemática é de proveniência grega e diz respeito a "conhecer, aprender". O termo temo mathema temu m significado de "conhecimento" e todos os modelos de entendimento. Menciona-se que a matemática manifestou-se na Mesopotâmia, e no Egito. Surgiu como uma matéria para inter-relacionar-se com a Aritmética e a Trigonometria, pois a partir desse contexto a matemática começou a engendrar na vida do ser humano. Pois Aranão afirma:

O conceito numérico abstrato aparece progressivamente na Mesopotâmia e no Egito a partir do terceiro milênio a.C: cada número é associado ao sistema de unidades, cria-se a representação ('dois" de 'duas ovelhas'). Portanto os primeiros sistemas de escrita, surgiram para atender a necessidade de calcular, dividir e repartir a riqueza material da sociedade, ou seja, para que uma sociedade possa criar uma escrita, é preciso que haja necessidades materiais (ARANÃO, 2004.p 23).

Pois Aranão (2004), recomenda que seja dada ao ensino e aprendizagem de Matemática, uma relação com os fatos e circunstâncias atuais, pois, não se devem ignorar os exemplos que a vida cotidiana empresta aos alunos e professores, exemplos esses reais e verdadeiros.

Somente assim, segundo esse autor, os alunos poderão sempre estar em sintonia com os fatos e profundamente motivados aos estudos, principalmente, se fazendo 
uma correlação do cotidiano com os conteúdos, utilizando a ludicidade dependendo do assunto a serem abordados. (14)

É de suma importância os profissionais da educação matemática, estar atentos ao que os alunos aprendem a aprender, isto é, que sejam capazes de raciocinar e interpretar, que estejam aptos a enfrentar as dificuldades que vão aparecendo a todo instante. Jogos também fazem parte do rol de atividades que possibilitam a criatividade dos alunos. São bastante úteis as brincadeiras ou jogos em forma de quebra-cabeças. Proporcionam oportunidades diferentes de valorizar e estimular 0 raciocínio mental e forçar a agilidade de pensamento (ARANÃO. 2004 p.12).

Para que a aprendizagem matemática seja efetivada, vários mecanismos devem ser considerados, os exemplos que os alunos trazem das suas experiências anteriores não podem, nem devem ser desprezados. São sempre ricos em variações e formas criativas de aplicar conteúdos já estudados. Então, aprender a matemática na escola representa dar continuidade no processo de construção do conhecimento lógicomatemático adquirido desde cedo (15).

Weisz (2000), em seu livro o diálogo entre o ensino e aprendizagem, sugere ao professor quatro itens relevantes, que segundo a autora, contribui para que todos os alunos aprendam, e devem ser considerados em quaisquer disciplinas no momento de distinguir e planejar agradáveis momentos de aprendizagem, pois na aprendizagem matemática, principalmente quando forem manipular os jogos não poderá ser diferente: segundo Weisz (2000),

Uma atividade é considerada uma boa situação de aprendizagem quando: 1. Os alunos precisam pôr em jogo tudo o que sabem e pensam sobre o conteúdo em torno do qual o professor organizou a tarefa; 2. Os alunos têm problemas a resolver e decisões a tomar em função do que se propõem a produzir; 3. O conteúdo trabalhado mantém as suas características de objeto sociocultural real;4. A organização da tarefa garante a máxima circulação de informação possível entre os alunos, por 
isso as situações propostas devem prever o intercâmbio, a interação entre eles. (2000 apud. Brasília/MEC, 2001, p.158)

Isso só acontece quando o professor refletir sobre sua prática pedagógica e propor aulas diferenciadas em sala de aula, porém com o objetivo melhorar a sua prática pedagógica e buscando o aperfeiçoamento da sua profissão.

\subsection{OS JOGOS NA EDUCAÇÃO MATEMÁTICA}

Em sua etimologia, a palavra jogo vem de jocu, substantivo que significa gracejo. Como percebido, denota divertimento, passatempo com regras que devem ser respeitadas. Pode ser considerada uma metáfora da vida, pois envolve manobras, oscilação, balanço, entre outras situações que se fazem presentes na vida real ( ANTUNES, 2002).

Para D'Ambrósio, de acordo com seus estudos e pesquisas enfatizando discussões do ensino tradicional da matemática, ganhou vários prêmios nacionais e internacionais e tendo uma contribuição da educação matemática. em seu livro Educação Matemática- da Teoria à Prática no ano de 1996, vem enfatizar um novo paradigma de educação, inovações e reflexões sobre prática docente ao ensino e aprendizagem da matemática.

Pois D’Ambrósio (1996),

Mas sem dúvida o racional, isto é, aquilo que se aprendeu nos cursos, incorpora-se à prática docente. $\mathrm{E}$ à medida que a vamos exercendo, a crítica sobre ela, mesclada com observações e reflexões teóricas, vai nos dando elementos para aprimorá-la (D’AMBRÓSIO 1996, p.91).

Segundo Araújo (1992, p. 64), "jogo é uma atividade espontânea e desinteressada, admitindo uma regra livremente escolhida, que deve ser observada, ou um obstáculo deliberadamente estabelecido, que deve ser superado". Assim, o jogo, ao mesmo tempo em que pressupõe liberdade de ação, necessita ter finalidade para vencer os obstáculos que se interpõem no contexto. 
Nesse momento, ela utiliza o jogo não somente como uma representação do que viveu, mas uma vivência única.

Kishimoto (2006) colabora com essa reflexão quando destaca que o jogo, para as crianças, tem um fim em si mesmo, não visa a um resultado final. O que importa para a criança que brinca (joga) é o ato da diversão em si, não a aquisição de conhecimento nem o desenvolvimento de qualquer habilidade.

Smole (2007) lembra que, a utilização de jogos na escola não é algo novo, assim como é bastante conhecido o seu potencial para o ensino e aprendizagem em muitas áreas do conhecimento. Assim, a mesma preconiza que,

O trabalho com jogos é um dos recursos que favorece 0 desenvolvimento da linguagem, diferentes processos de raciocínio e de interação entre os alunos, uma vez que durante um jogo cada jogador tem a possibilidade de acompanhar o trabalho de todos os outros, defenderem pontos de vista e aprender a ser crítico e confiante em si mesmo (SMOLE. 2007, p.1).

Assim, pode se considerar que os jogos ao serem utilizados no contexto escolar, podem ser transformados em riquíssimos recursos que subsidiarão o trabalho do educador.

Lara (2003, p.21), alerta aos educadores que se o ensino da matemática for considerado por estes, como um processo que contribui para o desenvolvimento do raciocínio lógico, estimular o pensamento independente, desenvolver a criatividade, a capacidade de manejar situações reais e resolver diferentes tipos de problemas, com certeza, há de ser buscar estratégias alternativas de trabalhar a matemática na escola.

Entre os recursos didáticos citados nos Parâmetros Curriculares Nacionais (PCN) destacam-se os "jogos". Segundo BRASIL, volume 3, não existe um caminho único e melhor para o ensino da Matemática, no entanto, conhecer diversas possibilidades de trabalho em sala de aula é fundamental para que o professor construa sua prática. 
De acordo com Lara (2003), o que se sabe é que os jogos, ultimamente, vêm ganhando espaço nas escolas numa tentativa de trazer o lúdico para dentro da sala de aula. A pretensão da maioria dos professores, com a sua utilização, é a de tornar as aulas mais agradáveis com o intuito de fazer com que a aprendizagem torne-se algo fascinante.

Além disso, as atividades lúdicas podem ser consideradas como uma estratégia que estimula o raciocínio levando o aluno a enfrentar situações conflitantes relacionadas com o seu cotidiano e, também, a utilização dos jogos vem corroborar o valor formativo da Matemática, não no sentido apenas de auxiliar na estruturação do pensamento e do raciocínio dedutivo, mas, também, de auxiliar na aquisição de atitudes.

Guzmán (1986), expressa muito bem o sentido que essa atividade tem na educação matemática: O interesse dos jogos na educação não é apenas divertir, mas sim extrair dessa atividade matérias suficientes para gerar um conhecimento, interessar e fazer com que os estudantes pensem com certa motivação.

Desse modo, acredita-sé que através dos jogos, é possível desenvolver no aluno, além de habilidades matemáticas, a sua concentração, a sua curiosidade, a consciência de grupo, o coleguismo, o companheirismo, a sua autoconfiança e a sua autoestima.

A utilização de atividades lúdicas em aulas de Matemática, além dos aspectos cognitivos relevantes para a sua aplicação, não deve ignorar ou menosprezar o aspecto afetivo, desencadeado pela ação do jogo, na aproximação dos jogadores. Essa ocorrência é verificada pelos ensinamentos de Piaget (1966-1974) e pontuados por Brenelli (1991, p 23) como "... em toda conduta humana o aspecto cognitivo é inseparável do aspecto afetivo, compreendido como a energia da ação que permeia a motivação, o interesse e o desejo."

Para Moura (1994), o jogo possibilita a aproximação do sujeito ao conteúdo científico, através da linguagem, informações, significados culturais, compreensão de regras, 
imitação, bem como pela ludicidade inerente ao próprio jogo, assegurando assim a construção de conhecimentos mais elaborados.

Para Kishimoto (2004),

A utilização do jogo potencializa a exploração e a construção do conhecimento, por conta com a motivação interna, típico do lúdico, mas o trabalho pedagógico requer a oferta de estímulos externos e a influência de parceiros bem como a sistematização de conceitos em outras situações que não jogos. Ao utilizar, de modo, metafórico, a forma lúdica (objeto suporte de brincadeira) para estimular a construção do conhecimento, o brinquedo educativo conquistou um espaço definitivo na educação infantil (KISHIMOTO 2004, p. 43).

Para MOURA (apud) Kishimoto (1993) "[...] a criança, adolescente procura o jogo como uma necessidade e não como distração [...]. É pelo jogo que a criança e o adolescente se revelam." A partir daí percebe-se que tanto a criança quanto o adolescente necessitam do brincar e se esse brincar é oportunizado em sala de aula, fazendo a relação entre o conteúdo que deve ser desenvolvido e a forma como ser aprendido, assimilado e construído pelo aluno, tem-se maior probabilidade de que a aprendizagem se dê com mais satisfação e de forma prazerosa para o educando. $O$ educador, por sua vez, terá uma forma mais atraente de apresentar os conteúdos.

De acordo com os Parâmetros Curriculares Nacionais de matemática (1997)

Um aspecto relevante nos jogos nas aulas de matemática é o desafio genuíno que eles provocam no aluno, que gera interesse e prazer. Por isso, é importante que os jogos façam parte da cultura escolar, cabendo ao professor analisar e avaliar a potencialidade educativa dos diferentes jogos e o aspecto curricular que se deseja desenvolver (BRASIL, 1997,48-49). 
Entende-se, portanto, que a aprendizagem deve acontecer de forma interessante, prazerosa e significativa, um recurso que possibilita isso, segundo as referências acima, são os jogos.

Pois, Regina Célia Grando na sua Dissertação de Mestrado na UNICAMP, sobre o estudo dos "Jogo e suas possibilidades metodológicas no processo ensinoaprendizagem", vem enfatizar o papel metodológico do jogo no processo ensino e aprendizagem da matemática, na qual esse estudo foi muito relevante para o Brasil e em outros países sob uma visão crítica da problemática do ensino da matemática no contexto em sala de aula , no Brasil atual. Pois Grando afirma:

Quando nos referimos à utilização dos jogos nas aulas de matemática como suporte metodológico, consideramos que tenha utilidade em todos os níveis de ensino. O importante é que os objetivos com o jogo estejam claros, a metodologia a ser utilizada seja adequada ao nível que se está trabalhando e, principalmente, que represente uma atividade desafiadora ao aluno para o desencadeamento do processo (GRANDO 2008, p 25).

Dessa forma, muitos dos conteúdos trabalhados em Matemática no Ensino Fundamental, por exemplo, não são propriamente novidades para as crianças. Elas já têm alguma ideia sobre eles, calcada no senso comum. “... é importante destacar que a matemática deverá ser vista pelo educando como um conhecimento que pode favorecer o desenvolvimento do seu raciocínio, de sua capacidade expressiva, de sua sensibilidade estética e de sua imaginação" (PCN’S 1998).

Na sua Tese de Doutorado no ano 2000, vem enfatizar uma investigação através de uma pesquisa de campo para resgatar competências e habilidades no ensino e aprendizagem de matemática, pois a prática pedagógica do professor vai se aperfeiçoando quando ele se apropria dos jogos matemáticos no ato de ensinar e os objetivos da pesquisa dela são: 
- Investigar as possibilidades do desenvolvimento do trabalho pedagógico, baseado em jogos e resolução de problemas;

- Evidenciar o processo de construção de procedimentos e conceitos, pelos sujeitos, a partir das intervenções pedagógicas realizadas no ambiente da sala de aula de matemática;

- Analisar os aspectos metodológicos do trabalho com os jogos no ensino da matemática (GRANDO 2000, p.61).

Sua pesquisa estudo de caso com 08 educandos do da $6^{\underline{a}}$ série, que hoje é é $7^{\circ}$ ano de uma escola em Campinas São Paulo, eles foram avaliados por métodos piagetiano, que concluiu-se que os jogos matemáticos tem a função de contribuir na meditação da prática pedagógica do professor na sua prática pedagógica, quebrando paradigmas e que é possível através dos jogos matemáticos acontecer uma aprendizagem significativa, atrativa, divertida no envolvimento dos alunos nas atividades de jogos matemáticos.

\section{AS CONCEPÇÕES DE PIAGET E VYGOTSKY NA APRENDIZAGEM DA MATEMÁTICA}

Jean William Fritz Piaget, nasceu em Neuchâtel- Genebra, 09 de agosto de 1896 e faleceu em 1980. Era biólogo e psicólogo. fundou a Epistemologia Genética, quer dizer como acontece o processo da aquisição do conhecimento e o desenvolvimento da inteligência. Realizou estudos empíricos sobre o pensamento infantil e o raciocínio lógico, no qual foi comprobado cientificamente através de seus experimentos, que a criança constrói seu próprio conhecimento e tem sua maneira própria de raciocínio. Também, pois para Piaget (1978),o pensamento lógico matemático é uma alteração da função psíquica da criança sobre o ambiente em que se insere, já que ele considera duas formas de compreender as experiências ligadas as ações, a seguir :

1. Experiências físicas: inclui a manipulação do sujeito com o objeto. exemplo, comparação e cores, e outros... 
2. Experiências lógico matemáticas: só há informação a apartir de suas próprias ações, das relações que estabelece quando o sujeito age sobre o objeto. A ação sobre o objeto é indispensável para a compreensão. Pois a ação é determinante para que há um aprendizado, na qual o educando possa refletir sobre o que levou a agir através de um determinado problema. Para entender melhor le estudou sobre os estágios do desenvolvimentos:

1. PERÍODO SENSÓRIO MOTTOR - do nascimento aos 02 anos.

2. PERÍODO OPERATÓRIO - dois estágios

2.1. PRÉ-OPERATÓRIO - de 02 a 07 anos de vida.

2.2. OPERATÓRIO CONCRETO - de 07 a 12 anos de vida.

3. OPERATÓRIO FORMAL - de 12 anos em diante.

No primeiro estágio, a criança é caracterizada pelo egocentrismo do pensamento.No segundo estágio, a criança é capaz de realizar certas operações de Reversibilidade, que é a capacidade que a criança tem de conseguir resolver problemas de conservação de quantidades. Segundo PIAGET (1973),

O papel inicial das ações e das experiências lógico matemáticas concretas é precisamente de preparação necessária para chegar se ao desenvolvimento de espírito dedutivo, e isto por duas razões. A primeira é que as operações mentais ou intelectuais que intervém nestas deduções posteriores derivam justamente das ações: ações interiorizadas, e quando esta interiorização, junto com as coordenações que supõem, são suficientes, as experiências lógico matemáticas enquanto ações materiais resultam já inúteis e a dedução interior se bastará a si mesmo. A Segunda razão é que a coordenação de ações e as experiências lógico matemáticas dão lugar, ao interiorizar-se, a um tipo particular de abstração que corresponde precisamente a abstração lógica e matemática (PIAGET 1973, p.57). 
Isso significa que a criança tem a capacidade de perceber a conservação de uma quantidade como: massa, volume, área, números que caracterizam os objetos e costuma desenvolver a partir dos 06 a 07 anos de vida.

Já para Para Lev Semyonovich Vygotsky, psicólogo, que nasceu em 1896 em Mosco una Rússia e faleceu em 1934, e seu trabalho foi todo sobre Pensamento e Linguagem, na qual, são dois princípios relevantes na associação da criança com os jogos: os preceitos e a conjuntura imaginária que eles simbolizam.

Quanto aos preceitos, o autor destaca, que mais adiante da própria carência de seguir regras, adaptar-se a elas e ter concussões com sua inerente cultura (pois o que é consentido em um desenfado em algum local pode não ser concedido em outro), o acatamento é algo que foi "combinado" antes do jogo principiar. A condição imaginária que os jogos favorecem, segundo Vigotsky, força a criança a encontrar respostas para aquilo que vivência. As situações de aprendizagem devem priorizar atividades que permitem que os alunos tragam suas experiências e seus conhecimentos espontâneos, mediantes atividades de jogos, que ocorre pela mediação de um adulto na Zona de Desenvolvimento Potencial da criança. Para Vygotsky(1991),

A zona de desenvolvimento proximal caracteriza-se pela distância entre o nível real (da criança) de desenvolvimento determinado pela resolução de problemas independentemente e o nível de desenvolvimento potencial determinado pela resolução de problemas sob a orientação de adultos ou em colaboração com companheiros mais capacitados (VYGOTSKY 1991, P.97).

Pois para Vygotsky, os jogos tem uma grande influencia no aspecto positivo na aprendizagem da criança, pois as atividades lúdicas tem uma função muito significativa para o progresso cógnito, social e amorável da criança incrementando a Zona de Desenvolvimento Proximal, permitindo a criança implementar habilidades e um conjunto de saberes socialmente que passam a ser internalizados. 
Nesse àpice, a criança manuseia o jogo não exclusivamente como uma atuação do que viveu, mas uma aprendizagem única. Para Vygotsky, a ludicidade tem um papel social a alacridade da criança, concebendo um conhecimento de sua experiencia, para recriar o mundo mediante da imaginação.

\section{CONSIDERAÇÕES FINAIS}

Ao desenvolvimento deste trabalho, evidenciou-se que os jogos quando o professor se a própria, os educandos, deixam de serem receptores das explicações do professor e passam a terem uma atuação mais ativa no progresso de elaboração de conceitos matemáticos, já que muitas vezes a aquisição do conhecimento sucede das próprias elucubrações que o aluno elabora. Nessa idealização, o professor tem papel primordial, pois é ele quem determina os procedimentos pedagógicos que são cruciais para o desenvolvimento do processo de ensino e aprendizagem, evitando que as atividades abordem o "jogo pelo jogo".

Adiante disso, o professor deve-se estar vigilantes no apuramento do jogo e também debe-se saber lidar com os benefícios e malefícios que decotam estar evidenciados nos jogos. Incube ao professor desvanear e averiguar a fim de que o aluno tire o maior proveito desse tipo de atividade, pois o maior objetivo é que o educando tenha um aprendizado significativo em seu processo, desenvolvendo suas habilidades e competências em sala de aula em uma unidade de ensino. $O$ jogo tem uma grande contribuição para o aperfeiçoamento da prática pedagógica do professor e uma aprendizagem significativa na compreensão dos conteúdos na disciplina de matemática.

Para finalizar é importante lembrar que, estamos na sumidade da evolução científica e tecnológica e, em conformidade no vértice da insatisfação dos nossos educandos. Assim, de acordo com o ofício que o professor distende é manumitir a vontade de aprender e, mais exclusivamente em estudar Matemática. É inconcebível que continuemos aceitando que um aluno que possibiliza, perfeitamente, dar troco, cuidar de sua "mesada" ou comprar um "rancho" dentro de seu orçamento - refiro-me a crianças, adolescentes e adultos - não consiga resolver problemas envolvendo 
conceitos matemáticos. Pois a aplicabilidade do jogo, trazendo peripécias do contexto do aluno, venha beneficiar toda a sua gama de conhecimento que foi construída fora da escola e muitas das vezes, é desconsiderada em sala de aula.

Pretende-se, também, que, através desta análise e execução de jogos apresentados envolvendo alguns conteúdos estudados no Ensino Fundamental II, os envolvidos percebam os benefícios encontrados e objetivos alcançados durante sua execução e a eficácia da utilização de jogos na disciplina de Matemática. Crê-se que o uso de jogos tem o objetivo de fazer com que os alunos gostem de aprender Matemática. Nas aulas com jogos, os alunos passam a ser elementos ativos do seu processo de aprendizagem, vivenciando a estruturação do saber e deixando de ser um mero ouvinte passivo para ser um indivíduo pensante e ativo no processo ensino e aprendizagem.

Acredita-se que os Jogos são instrumentos admissíveis e tocáveis a educação Matemática sendo de grande utilidade no dia a dia escolar. Hoje devemos dar a verdadeira importância ao lúdico, porque é uma necessidade permanente de qualquer pessoa em qualquer idade, e que não pode ser vista somente como diversão. Para nós educadores a ludicidade têm outra visão, além do que ela representa para a maioria das pessoas, temos como fonte de aprendizagem.

Diante desta conjuntura, esperamos que este estudo contribua de maneira qualitativa para subsidiar o trabalho docente dos profissionais que acreditam na mudança da qualidade educativa, principalmente no que diz respeito à educação matemática.

\section{REFERÊNCIAS}

AMBROSIO, Ubiratan. Educação Matemática da teoria a prática. 12.ed. Campinas: Papirus, 1996.

ARAÚJO, Vânia Carvalho de. 0 jogo no contexto da educação psicomotora. São Paulo: Cortez, 1992. 
ARANÃO, Ivana V. D. A matemática através de brincadeiras e jogos. 5 . ed. Campinas: Papirus, 2004.

AZEVEDO, M.V. R. Jogando e Construindo Matemática: a influência dos jogos e materiais pedagógicos na construção dos conceitos em Matemática. São Paulo: Editora Unidas, 1993.

BORIN, J. Jogos e resolução de problemas: uma estratégia para as aulas de matemática. São Paulo: IME-USP;1996.

BRASIL. Secretaria da Educação Fundamental. Parâmetros Curriculares Nacionais: Matemática - Brasília: MEC / SEF, 1998.

BRASIL. Ministério da Educação e do Desporto. Parâmetros curriculares brasileiros. Brasília, 1999.

CAILLOIS, R. Os jogos e os homens: a máscara e a vertigem. Lisboa: Edições Cotovia, 1990, tradução: José Garcez Palha.

CENTURIÓN, M. et al. Jogos, Projetos e Oficinas para educação Infantil. São Paulo: FTD, 2004.

GRANDO, R. C. A construção do conceito matemático no jogo. (Texto fotocopiado), s/d.

O jogo e suas possibilidades metodológicas no processo ensino/aprendizagem da Matemática. Campinas: FE/UNICAMP. Dissertação de Mestrado, 1995.

O jogo e a Matemática no Contexto em Sala de Aula. São Paulo: Paulus. 2ª̂Ed., 2008.

GROENWALD, Claudia L. O.; TIMM, Úrsula Tatiana. Utilizando curiosidades e jogos >matemáticos em sala de aula. Disponível em: http://www.somatematematica.com.brAcesso: fev/2002 
HUIZINGA, J. Homo Ludens: o jogo como elemento da cultura. São Paulo: Ed. Perspectiva, 2ª edição, 1990, tradução: João Paulo Monteiro.

KAMII, Constance ; DECLARK, Georgia. Reinventando a aritmética: implicações da teoria de Piaget. São Paulo, Campinas: Papirus, 1992 . - Aritmética: Novas Perspectivas. Implicações da Teoria de Piaget. Papirus Editora, 2001.

KISHIMOTO citado por LUCENA, Ferreira De. Jogos e brincadeiras na Educação Infantil. Campinas: Papirus, 2004.

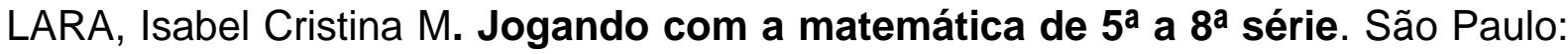
Editora Rêspel, 2003.

MACEDO, L.; PETTY, A. L. S. e PASSOS, N. C. 4 cores, senha e dominó: oficina de jogos em uma perspectiva construtivista e psicopedagógica. São Paulo: Casa do Psicólogo, 1997.

MATOS, J. M. e SERRAZINA, M. de L. Didática da Matemática: Recursos na aula de Matemática. Lisboa: Universidade Aberta, 1996.

MOURA, M. O. de. A construção do signo numérico em situação de ensino. São Paulo: USP, 1991.

A Séria Busca no Jogo: do Lúdico na Matemática. In $\mathrm{A}$ Educação Matemática em Revista. São Paulo: SBEM-SP, 1994, p.17-24.

SILVA, Mônica. Jogos Educativos. Campinas: Papirus, 2004.

STAREPRAVO. A.R. Jogando com a matemática: números e operações. Curitiba: Aymará, 2009

Piaget, J. (1982). O Nascimento da Inteligência na Criança, 4⿳亠丷a edição, Rio de Janeiro: Zahar. 
SMOLE. K. S.Jogos matemáticos de 1ํao 5a ano. Porto Alegre. Artemd. 2007

MICHAELIS.

Jogo.

Disponível

em:

http://michaelis.uol.com.br/moderno/portugues/index.

php?lingua $=$ portugues-

ortugues\&palavra=jogo >.Acesso em: 4 ago. 2010.

PIAGET, J. Comments in Mathematical Education, em A. G. Howson (ed) Proceedings of the Second, 1973b.

Programa de Formação de Alfabetizadores. Brasília: MEC.2001 São Paulo (Estado). Secretaria da Educação. Ler e escrever guia de planejamento e orientações didáticas professor alfabetizador: $1^{\circ}$ ano. 2 ed. São Paulo: FDE, 2012

TOLEDO. M.M. Teoria e prática de matemática. São Paulo: FTD, 2009

TELMA Weisz In.O diálogo entre o ensino e aprendizagem. São Paulo, Ática, 2000.

VYGOTSKY, L. S. A Formação Social da Mente. 4.Ed. tradução de José Cipolla Neto e outros. São Paulo: Martins Fontes, 1991.

Enviado: Março, 2019.

Aprovado: Junho, 2019. 